\title{
Effect of geometrical parameters of open microchannel surfaces on pool boiling heat transfer
}

\author{
Robert Kaniowski ${ }^{1}$, Robert Pastuszko ${ }^{1, *}$, and Lukasz Nowakowski ${ }^{1}$ \\ ${ }^{1}$ Kielce University of Technology, Faculty of Mechatronics and Mechanical Engineering, Al. 1000-lecia Państwa Polskiego 7, \\ PL-25-314 Kielce, Poland
}

\begin{abstract}
This study focuses on the effect of channel depth on the heat transfer coefficient during nucleate pool boiling. Experimental studies were performed for saturated deionized water, and Novec-649 as working fluids at atmospheric pressure. Copper surfaces were modified to form microchannels with different geometrical properties. The microchannels were from $0.2 \mathrm{~mm}$ to $0.4 \mathrm{~mm}$ deep, $0.3 \mathrm{~mm}$ wide and spaced every $0.1 \mathrm{~mm}$. The experiment was conducted for increasing heat flux up to the critical heat flux point. The surface modification provided an appreciably higher heat transfer coefficient compared to the smooth surface for all boiling liquids. The maximum heat transfer coefficient obtained exceeded $60 \mathrm{~kW} / \mathrm{m}^{2} \mathrm{~K}$.
\end{abstract}

\section{Introduction}

A high demand for effective heat removal from, in particular, microelectronic chips determines the development of small-size heat exchangers harnessing the liquid to gas phase transition. Thus far this has been one of the most effective forms of thermal energy transfer at the temperature of the heated surface maintained constant. The heated surface, however, needs to be modified and provided with an enhanced structure. A great many publications have reported the outcomes of boiling heat transfer research for various working fluids on different surface types and enhancement. Yet no simple structure has been proposed so far that would provide high heat transfer coefficients for different boiling liquids within a broad heat flux range. One of simpler but effective surface modifications involves cutting parallel grooves of $0.2-1 \mathrm{~mm}$ width and much the same depth range. As a result, a system of open microchannels is produced - the sites of vapour bubble intensive nucleation, growth and departure. Below, examples of the latest results from the literature-reported research on boiling heat transfer in open microchannels are discussed.

Jaikumar and Kandlikar [1] performed an experiment on surfaces that had three different inter-fin channel widths, $300 \mu \mathrm{m}, 500 \mu \mathrm{m}$ and $762 \mu \mathrm{m}$, with water at atmospheric pressure. They studied the effect of the inter-fin channel width on the surface performance and heat transfer mechanisms in open microchannel surfaces with three coating configurations: sintered-throughout, sintered-fin-tops, and sintered-channels. The heat transfer coefficients obtained, up to $2900 \mathrm{~kW} / \mathrm{m}^{2} \mathrm{~K}$, were large relative to the structured $10 \times 10 \mathrm{~mm}^{2}$ area, which gives about $1000 \mathrm{~kW} / \mathrm{m}^{2} \mathrm{~K}$ relative to the total surface of heat transfer $\left(17 \times 17 \mathrm{~mm}^{2}\right)$
In $[2,3]$, the authors performed an experiment with water and ethanol at atmospheric pressure. The surfaces studied were $\Omega$-shaped copper structures with circular cavities and narrow exit grooves upwards. These surfaces noticeably increase the number of active nucleation sites and are able to maintain a stable supply of liquid to the channels at large heat fluxes, which leads to high CHF.

The authors of [4] studied pool boiling of Novec7300 fluid and self-rewetting water-heptanol mixtures on a bare copper surface and copper surface coated with copper-plated nanofibers. Heat transfer coefficients were found to be higher for the surface with the copper-plated nanofiber.

Research on pool boiling heat transfer with water, ethanol, FC-72 and Novec-649 from various structured surfaces $[5,6]$ and boiling heat transfer with FC-72 flowing in narrow channels [7-9] has been conducted at the Kielce University of Technology for more a decade.

\section{Experimental investigations}

\subsection{Test surfaces}

The specimens with test surfaces were made of copper and had parallel grooves with a constant pitch and a cutter of $0.3 \mathrm{~mm}$ in diameter (CNC machining process), Fig.1. The test section consists of a $32.5 \times 32.5 \mathrm{~mm}^{2}$ square copper specimen with a $26.8 \times 26.8 \mathrm{~mm}^{2}$ boiling region as shown in Fig 1a. Table 1 compiles the surface codes and specifications according to Fig. $1 \mathrm{~b}$.

Talysurf CCI - Lite Non-contact 3D Profiler, a system providing optical, non-contact measurement of geometrical surface structures, was used to determine the roughness profile, shown in Fig. 2. Mean roughness was $0.127 \mu \mathrm{m}$.

Corresponding author: tmprp@tu.kielce.pl 

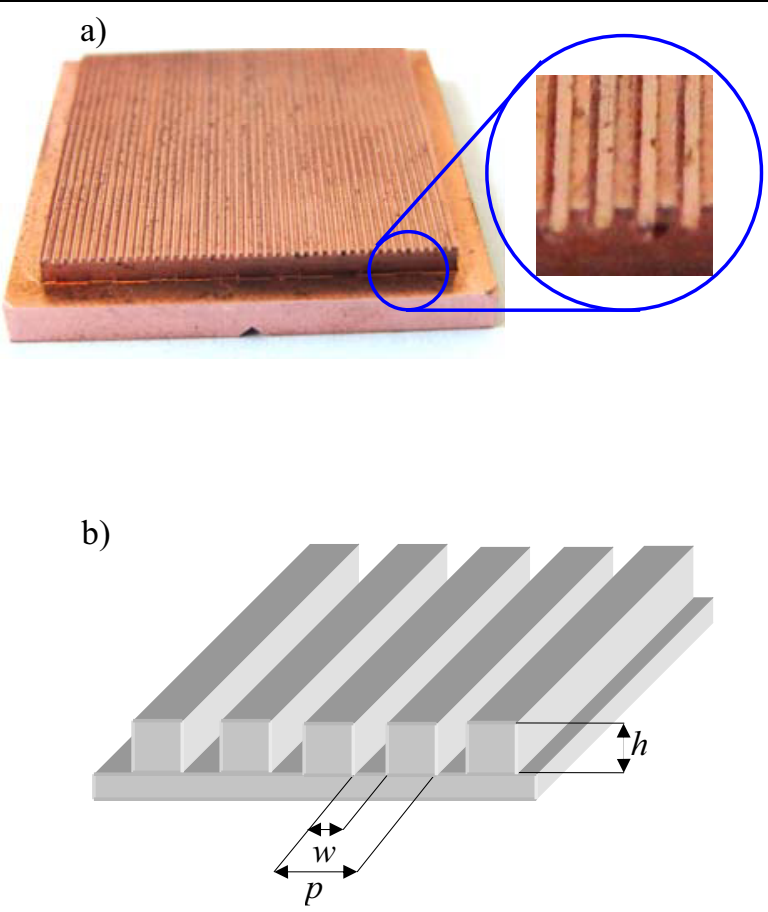

Fig. 1. a) View of MC-0.3-0.3-0.6 specimen, b) dimension symbols.

a)
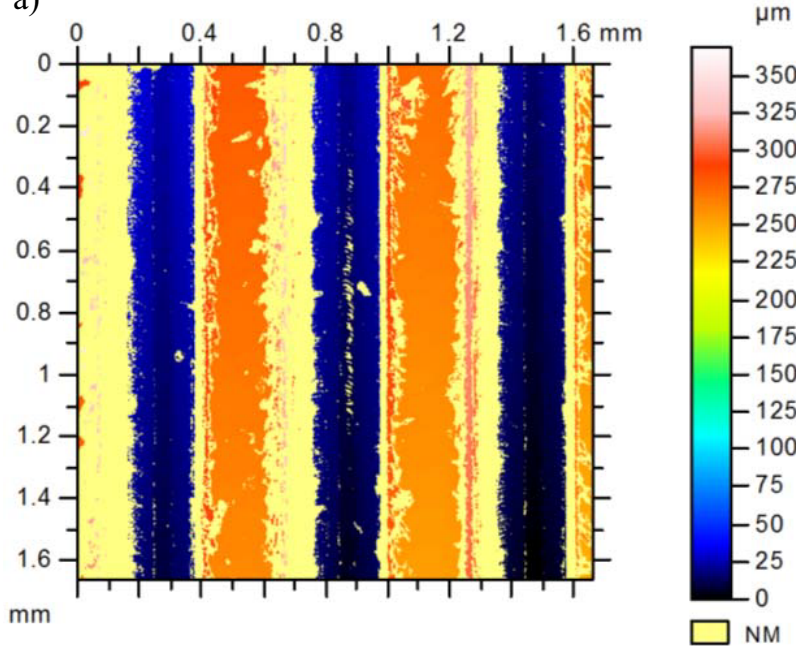

b)
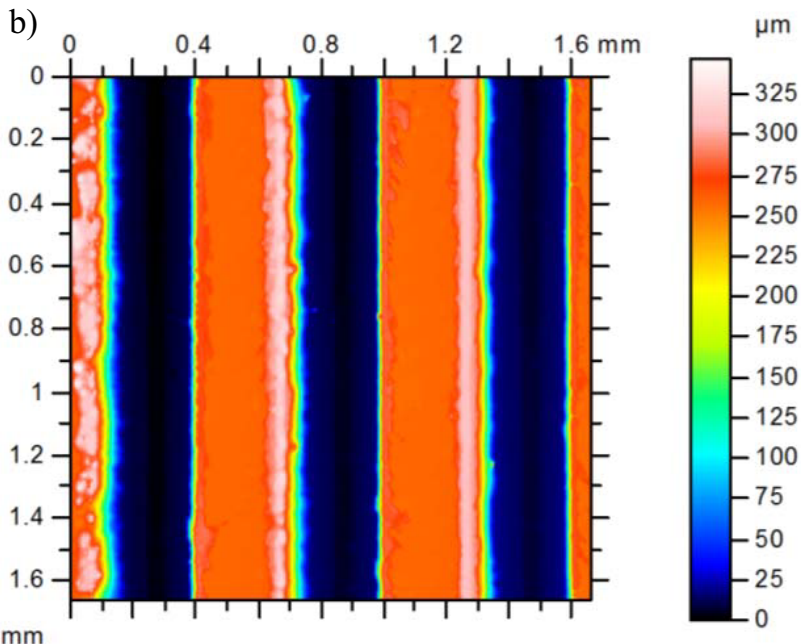

Fig. 2. Roughness profile of surface microchannel, a) microchannel top, b) microchannel bottom.
Table 1. Surface codes and specifications.

\begin{tabular}{|c|c|c|c|}
\hline Specimen code & $\begin{array}{c}w \\
\mathrm{~mm}\end{array}$ & $\begin{array}{c}h \\
\mathrm{~mm}\end{array}$ & $\begin{array}{c}p \\
\mathrm{~mm}\end{array}$ \\
\hline $\mathrm{MC}-0.3-0.4-0.6$ & 0.3 & 0.4 & 0.6 \\
\hline $\mathrm{MC}-0.3-0.3-0.6$ & 0.3 & 0.3 & 0.6 \\
\hline $\mathrm{MC}-0.3-0.2-0.6$ & 0.3 & 0.2 & 0.6 \\
\hline
\end{tabular}

\subsection{Experimental apparatus}

The measurements were performed on the set-up shown in Figs 3 and 4. The set-up was designed to determine the temperature difference between the liquid and the heated surface and to find the heat flux. These parameters are necessary to be able to plot boiling curves. Heat transfer on the surfaces with microchannels was studied for nucleate pool boiling. The level of liquid above the specimen surface was more than $50 \mathrm{~mm}$.

Prior to measurement, the fluid was degassed through boiling maintained for about 15 minutes. Measurement data were recorded after all temperature values stabilised. The heat flux was increased during the tests up to the boiling crisis level.

Diameter of the heating bar corresponded to the diagonal of the specimen base. A $1000 \mathrm{~W}$ electric cartridge heater $19 \mathrm{~mm}$ in diameter and $130 \mathrm{~mm}$ in length was installed into the bar.

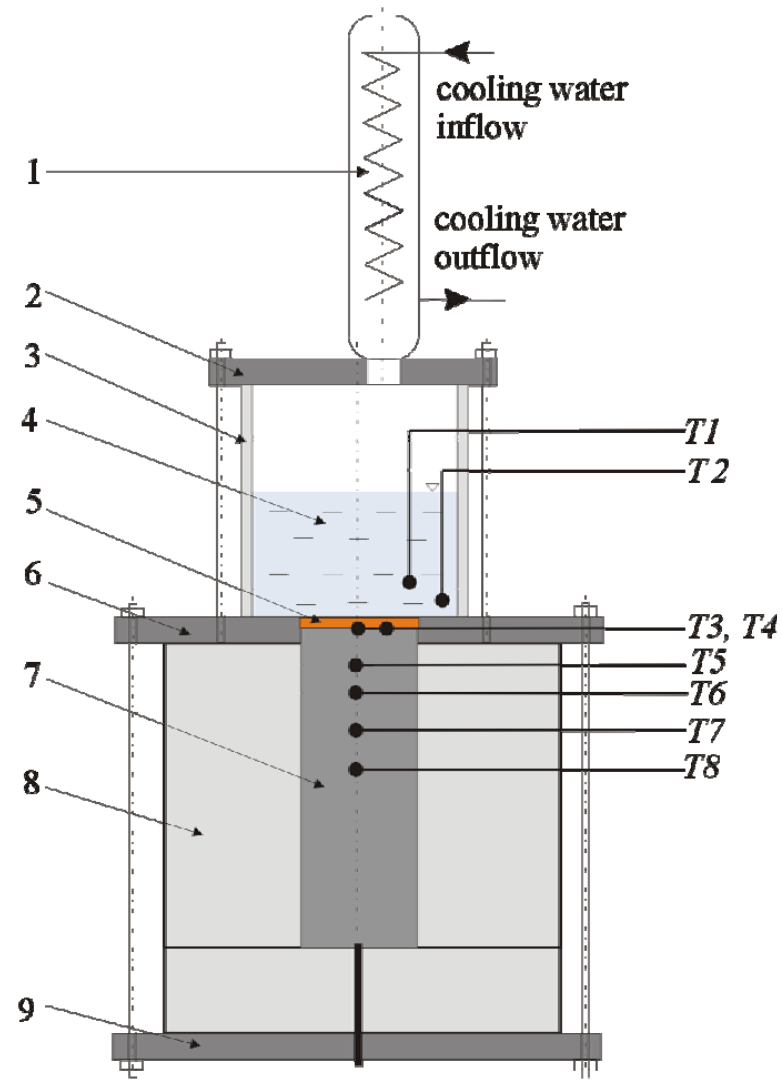

Fig. 3. Main module of pool boiling experimental stand: $1-$ condenser, 2 - top flange 3 - glass vessel, 4 - test fluid, 5 - test surface, 6 - teflon lid, 7 - copper bar with cartridge heater, 8 insulation, 9 - teflon base. 


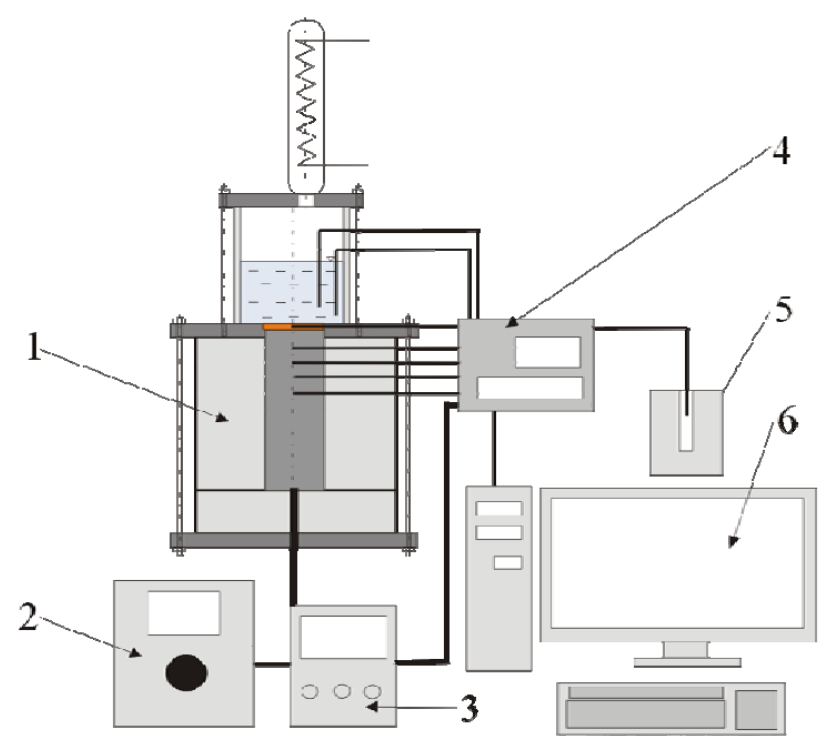

Fig. 4. Pool boiling measurement stand: 1 - main module, $2-$ autotransformer, 3 - wattmeter, 4 - data logger, 5 - dry-well calibrator, 6-PC.

The estimated uncertainties were as follows:

- low heat flux $\left(2 \mathrm{~kW} / \mathrm{m}^{2}\right)$ : heat flux $\pm 35 \%$, heat transfer coefficient $\pm 40 \%$,

- high heat flux $\left(800 \mathrm{~kW} / \mathrm{m}^{2}\right)$ : heat flux $\pm 2.1 \%$, heat transfer coefficient $\pm 2.4 \%$.

\section{Results}

In order to mount the specimen on the heating bar, a layer of tin with thickness $\delta_{S n}=0.1 \mathrm{~mm}$ and thermal conductivity $\lambda_{S n}=66.5 \mathrm{~W} /(\mathrm{mK})$ was used. The linearity of temperature distribution between thermocouples T3 and T8 was checked, Fig. 5, and the coefficient of determination $\mathrm{R}^{2}$ was between 0.9910 and 0.9936 . This proves that one dimensional conduction heat transfer in the upper part of the heating bar is the reasonable dominant heat transfer mechanism.

With the assumption that the heat flow is onedimensional, the heat flux was calculated on the basis of the temperature gradient in the copper bar from:

$$
q=\lambda_{C u} \frac{\Delta T_{1}}{l_{T 5-T 8}},
$$

where: $l_{T 5-\mathrm{T} 8}=30 \mathrm{~mm}$ is the distance between thermocouples T5 and T8, Fig. 3; the temperature difference is given by:

$$
\Delta T_{1}=T_{T 8}-T_{T 5},
$$

The heat transfer coefficient is expressed as:

$$
\alpha=\frac{q}{\Delta T_{T 2}},
$$

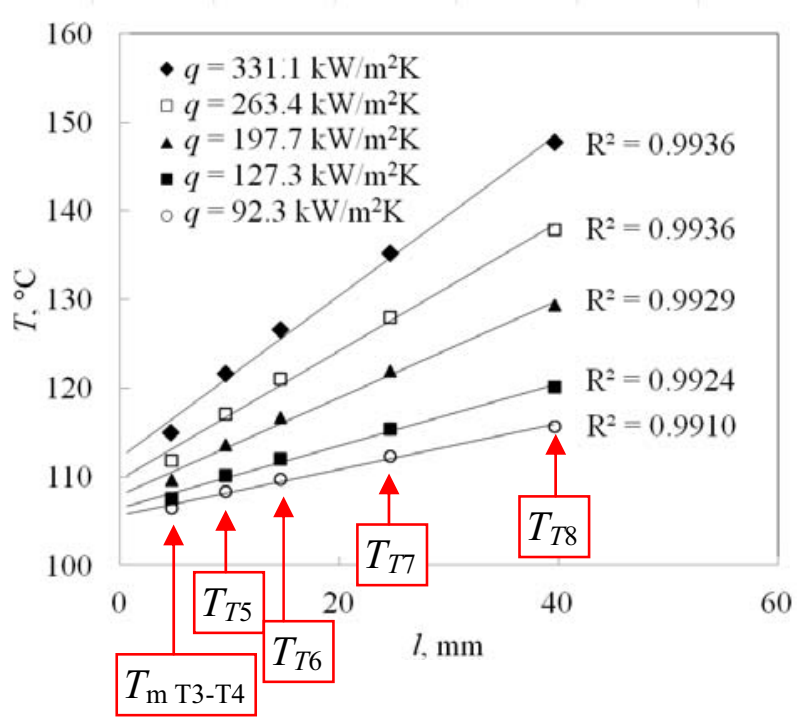

Fig. 5. Temperature vs. thermocouple location in the heating bar, water.

The difference between temperatures of the heated surface and liquid $\Delta T_{2}$ (superheat) is shown by the following equation, according to Fig. 3:

$$
\Delta T_{T 2}=\frac{T_{T 3}+T_{T 4}}{2}-\frac{T_{T 1}+T_{T 2}}{2}-q\left(\frac{\delta_{s}}{\lambda_{C u}}+\frac{\delta_{S n}}{\lambda_{S n}}\right)
$$

Figures 6 and 7 show the relationships between the heat transfer coefficient and heat flux and between the heat flux and temperature superheat at increasing heat flux on the $\mathrm{MC}$ surface for two boiling liquids. Compared with smooth surfaces, specimens with microchannels provided significant heat transfer enhancement, with heat transfer coefficient being dependent on the microchannel height. The best results were recorded for specimen MC-0.3-0.3-0.6, where the maximum heat transfer coefficient was $\alpha=64.4 \mathrm{~W} / \mathrm{m}^{2} \mathrm{~K}$ for $\Delta \mathrm{T} \sim 10.5 \mathrm{~K}$ with water. With Novec-649, the highest coefficient was $7.7 \mathrm{~W} / \mathrm{m}^{2} \mathrm{~K}$ for $\Delta \mathrm{T} \sim 11.5 \mathrm{~K}$.

For MC-0.3-0.3-0.6, the boiling incipience temperature was lower by about $5 \mathrm{~K}$ with water and $7 \mathrm{~K}$ with Novec-649.

Table 2 summarizes calculation results of constant $\mathrm{C}$ and the exponent $\mathrm{n}$ in the dependence for the value of the heat flux $q=C \Delta T^{n}$ for water and Novec-649 in relation to three MC surfaces and a smooth surface.

Heat transfer enhancement on the specimens with microchannels was confirmed by the ratio between heat transfer coefficient for the structured surface and that for the smooth surface. The coefficient values obtained were as follows: $\alpha_{\mathrm{enh}} / \alpha_{\mathrm{smt}}=8$ for MC-0.3-0.4-0.6, $\alpha_{\mathrm{enh}} / \alpha_{\mathrm{smt}}=$ 20.7 for MC-0.3-0.3-0.6, and $\alpha_{\mathrm{enh}} / \alpha_{\mathrm{smt}}=5.2$ for MC-0.3$0.2-0.6$ at superheat $\Delta \mathrm{T} \sim 8.5 \mathrm{~K}$ with water as the working fluid.

For Novec-649, the increase in coefficient values was similar. The $\alpha_{\text {enh }} / \alpha_{\text {smt }}$ ratio was 14 for specimen MC-0.3$0.4-0.6,14.7$ for $\mathrm{MC}-0.3-0.3-0.6$, and 10 for MC-0.3$0.2-0.6$ at superheat $\Delta \mathrm{T} \sim 10.5 \mathrm{~K}$. 
Table 2. Constant $\mathrm{C}$ and exponent $\mathrm{n}$ for function $q(\Delta T)$

\begin{tabular}{|c|c|c|c|}
\hline Specimen code & fluid & $C$ & $n$ \\
\hline MC-0.3-0.4-0.6 & water & 0.91 & 2.34 \\
\hline MC-0.3-0.3-0.6 & water & 2.571 & 2.44 \\
\hline MC-0.3-0.2-0.6 & water & 1.340 & 2.09 \\
\hline Smooth surface & water & 0.038 & 3.03 \\
\hline MC-0.3-0.4-0.6 & Novec-649 & 0.440 & 1.87 \\
\hline MC-0.3-0.3-0.6 & Novec-649 & 0.095 & 2.67 \\
\hline MC-0.3-0.2-0.6 & Novec-649 & 1.624 & 2.26 \\
\hline Smooth surface & Novec-649 & 0.038 & 2.21 \\
\hline
\end{tabular}

a)
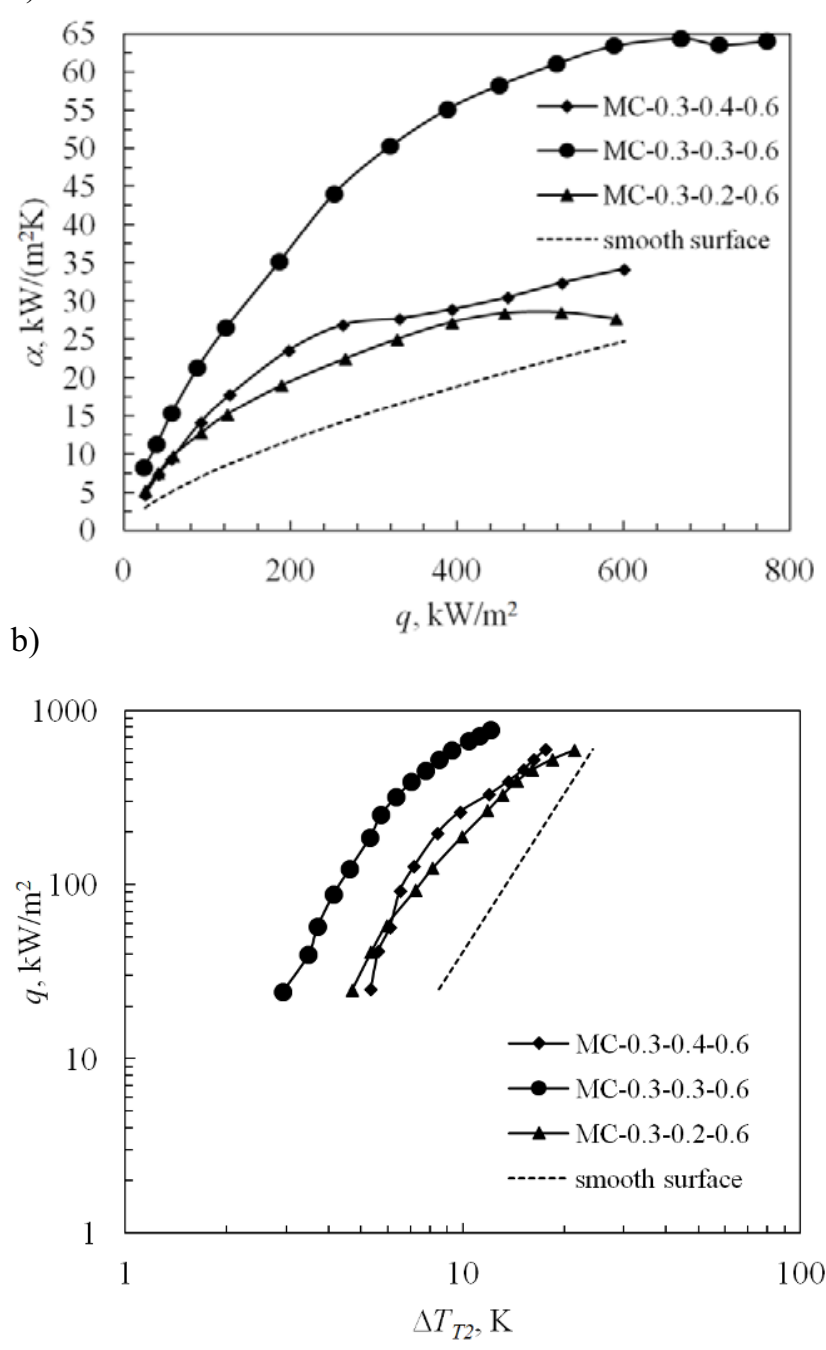

Fig. 6. Boiling curves for water, a) heat transfer coefficient vs. heat flux, b) heat flux vs. superheat.

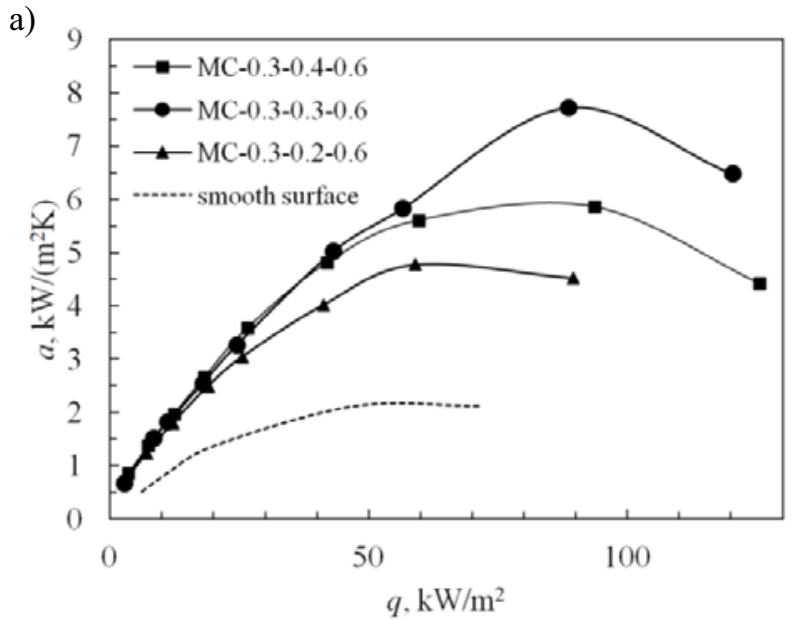

b)

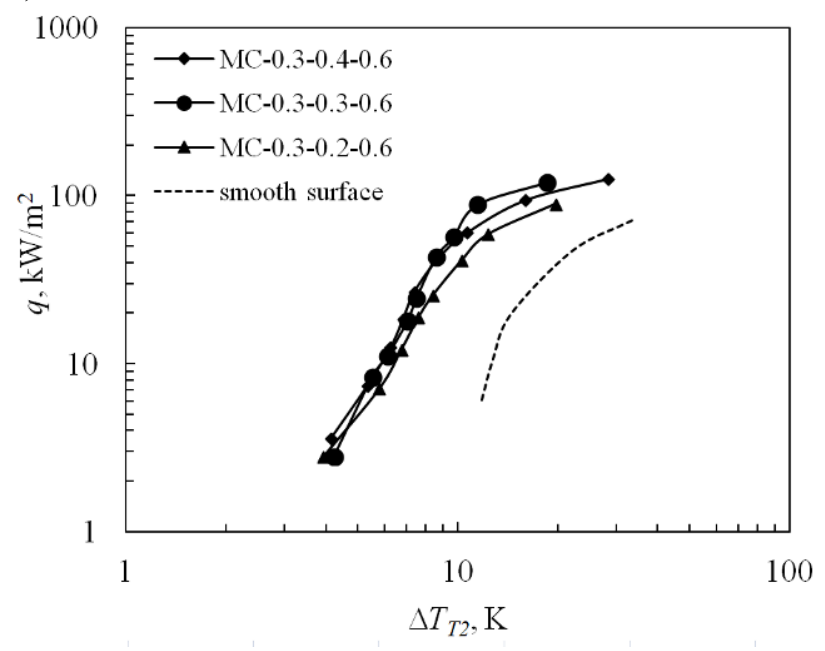

Fig. 7. Boiling curves for Novec-649, a) heat transfer coefficient vs. heat flux, b) heat flux vs. temperature difference.

The depth of the microchannels had a significant effect on heat transfer performance of the investigated surfaces. From among three surfaces with microchannels $0.2,0.3$ and $0.4 \mathrm{~mm}$ in depth, the best performance was provided by $0.3 \mathrm{~mm}$ deep microchannels. An increase in the depth of a microchannel leads to the rise in its bottom temperature, which is due to the reduced distance from the heater. As a result, nucleation is induced at lower heat fluxes and superheats and the heat transfer coefficient is higher. An increase in the microchannel depth implies an increase in the height of microfins forming the channel walls. Higher microfins cause a reduction in temperature at their tips, which reduces the intensity of vapour bubble generation from these surfaces.

\section{Conclusions}

The experimental studies discussed in this paper lead to the following conclusions:

- With water as the working fluid, heat transfer coefficients obtained for the surfaces with $0.3 \mathrm{~mm}$ deep microchannels were twice as high as those with microchannels 0.2 and $0.4 \mathrm{~mm}$ deep. 
- With Novec-649 as the working fluid, a similar HTC increase for the surface with a $0.3 \mathrm{~mm}$ deep microchannels was observed on the surface whose channels were the least shallow.

- Compared with the smooth surface, the increase in the heat transfer coefficient value for the best surface was 3.5 times as high (at constant heat flux).

- At the stable microchannel pitch and width, the choice of channel depth is vital for the intensity of heating the inflowing liquid and for the higher vapour generation rate on the microchannel bottoms and microfin tips.

- Experimental studies for other liquids, channel widths and pitches are necessary to check the effect of at least three geometrical parameters on the heat transfer process.

\section{Nomenclature}

$$
\begin{array}{ll}
C & - \text { constant } \\
\text { CHF } & - \text { critical heat flux } \\
h & - \text { microchannel height, } \mathrm{m} \\
l & \text { - distance, } \mathrm{m} \\
n & - \text { constant } \\
p & - \text { pitch, } \mathrm{m} \\
q & - \text { heat flux, } \mathrm{kW} / \mathrm{m}^{2} \\
T & - \text { temperature, } \mathrm{K} \\
w & - \text { width, } \mathrm{m}
\end{array}
$$

\section{Greek symbols}

$\alpha \quad$ - heat transfer coefficient, $\mathrm{W} /\left(\mathrm{m}^{2} \mathrm{~K}\right)$

$$
\begin{array}{ll}
\Delta T & \text { - difference of temperature, } \mathrm{K} \\
\delta & \text { - thickness, mm } \\
\lambda & \text { - thermal conductivity, } \mathrm{W} /(\mathrm{mK})
\end{array}
$$

$$
\begin{array}{ll} 
& \text { Subscripts } \\
\mathrm{Cu} & \text { - copper } \\
\text { enh } & \text { - enhancement } \\
S n & \text { - tin } \\
s & \text { - specimen } \\
s m t & \text { - smooth }
\end{array}
$$

\section{References}

1. A. Jaikumar, S. G. Kandlikar, Int. J. Heat Mass Transfer 95, (2016)

2. D. Deng, J. Feng, Q. Huang, Y. Tang, Y. Lian, Int. J. Heat Mass Transfer 99, (2016)

3. D. Deng, W. Wan, J. Feng, Q. Huang, Y. Qin, Y. Xie, App. Therm. Ing. 107, (2016)

4. R. P. Sahu, S. Sinha-Ray, S. Sinha-Ray, A. L. Yarin, Int. J. Heat Mass Transfer 95, (2016)

5. R. Pastuszko, Exp. Therm. Fluid Sci. 38, (2012)

6. R. Pastuszko, T. Wójcik, Exp. Therm. Fluid Sci. 63, (2015)

7. S. Hozejowska, R. Kaniowski, M. Poniewski, Exp. Therm. Fluid Sci.78, (2016)

8. M. Piasecka, Int. J. Heat Mass Transfer 81, (2015)

9. M. Piasecka, B. Maciejewska, Exp. Therm. Fluid Sci.78, (2015) 